\title{
CARACTERIZAÇÃO DO PERFIL ERITROCITÁRIO DE PORTADORES DE ANEMIA FALCIFORME POR ESPECTROSCOPIA RAMAN E MICROSCOPIA DE FORÇA ATÔMICA
}

\author{
Joel Félix Diniz ${ }^{1 *}$, Railson de Oliveira ${ }^{1}$, Franciné Maia ${ }^{2}$, Mariana P. M. A. Baroni ${ }^{3}$, Clenilton C. dos Santos ${ }^{1}$, Erivelton \\ Façanha da Costa $^{4}$, Luciana M.R. Alencar ${ }^{1}$
}

\begin{abstract}
${ }^{1}$ Departamento de Física, UFMA; ${ }^{2}$ Departamento de Ciências Naturais, Matemática e Estatística, UFERSA; ${ }^{3}$ Departamento de Ciências e Matemática, IFSP - campus São Paulo; ${ }^{4}$ Instituto Federal de Educação Ciência e Tecnologia da Bahia IFBA, Campus Irecê.

*joel_felix7@hotmail.com
\end{abstract}

\section{INTRODUÇÃO}

0 diagnóstico de doenças em seu estado inicial possibilita que sejam tratadas de forma mais eficiente e, para isso, a utilização de técnicas não convencionais como a Espectroscopia Raman (ER) vêm aumentando. A ER é uma técnica que apresenta diversas vantagens, principalmente de não necessitar da preparação elaborada das amostras, não ser evasiva, estudar micropartículas dentro de uma matriz homogênea, proporcionar a análise em um curto espaço de tempo, entre outros benefícios [1].

A anemia falciforme é uma doença genética que foi descrita pela primeira vez em 1910 por Herrick [2], porém já era conhecida na África anteriormente, seu local de origem (há cerca de 50 a 100 mil anos) [3]. É uma doença do grupo das hemoglobinopatias, extremamente comum, causada por uma alteração molecular no cromossomo 11 [4], que é a substituição do aminoácido acido glutâmico pelo aminoácido valina na posição 6 da cadeia B-globina (Fig. 1). Essa alteração faz com que a hemoglobina, presente nas hemácias, apresente uma deformação estrutural, comprometendo toda a distribuição de oxigênio pelo organismo.

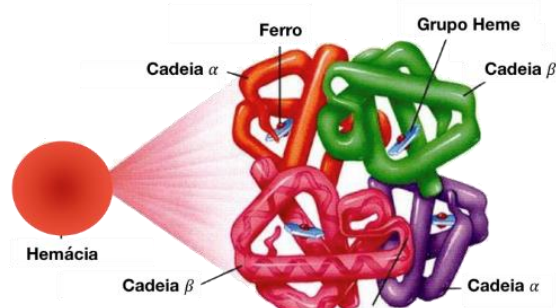

Figura 1. Estrutura da molécula de hemoglobina presente nos eritrócitos (hemácias ou glóbulos vermelhos.

Mesmo tendo surgido nos países do centro-oeste africano, na Índia e no leste da Ásia [5], essa mutação se espalhou pelo mundo em virtude da imigração forçada (do tráfico de escravos africanos) e dos movimentos populacionais em busca de melhores condições de vida. No Brasil, devido ao fato do país ter recebido uma vasta população de africanos, estima-se que 3 (três) em cada 100 (cem) pessoas são portadoras do traço de anemia falciforme e 1 (um) em cada 500 (quinhentos) negros brasileiros nasce com uma forma da doença [6], caracterizando-se como um problema de saúde pública.

Por ter origem na África, a anemia falciforme é predominante entre negros e pardos, mas, devido à miscigenação, ela atinge de forma significativa a etnia de brancos. No Brasil, segundo dados do Programa Nacional de Triagem Neonatal, nascem, a cada ano,
3.500 (três mil e quinhentas) crianças com anemia falciforme e 200.000 (duzentas mil) com traço falciforme. Os casos são mais comuns no Nordeste. 0 Estado em que há mais casos da doença é a Bahia, pois, a cada 650 (seiscentos e cinquenta) nascidos vivos, 1 (um) possui a doença. 0 Maranhão ocupa a $4^{\circ}$ (quarta) posição em casos, sendo que, de cada 1.400 (mil e quatrocentas) crianças nascidas, 1 (uma) tem a doença. Na região Sul, de cada 14.000 (catorze mil) nascidos, 1 (um) possui a doença. Um dos vários problemas relacionados à anemia falciforme é o elevado índice de morte entre bebês que nascem com a doença, podendo chegar a $10 \%$ (dez por cento) no Brasil [8].

Dados do Programa Nacional de Triagem Neonatal apresentam a gravidade da questão de saúde pública, como mostrados na Tabela 1.

\begin{tabular}{ll} 
Tabela 1 & \\
\hline Estados & Incidência \\
\hline Bahia & $1: 650$ \\
\hline Rio de Janeiro & $1: 1300$ \\
\hline Pernambuco, Maranhão, Minas Gerais e Goiás & $1: 1400$ \\
\hline Espírito Santo & $1: 1800$ \\
\hline São Paulo & $1: 4000$ \\
\hline Rio Grande do Sul & $1: 11000$ \\
\hline Santa Catarina e Paraná & $1: 13500$
\end{tabular}

Outro caso envolvendo a mutação da Hemoglobina $S$ é o traço falciforme, quando o indivíduo herda de um dos pais o gene da hemoglobina $\mathrm{A}$ e do outro o gene para a hemoglobina $\mathrm{S}$, uma condição comum no Brasil e considerada clinicamente benigna, porquanto os portadores não apresentam nenhuma anomalia física e sua expectativa de vida é semelhante ao da população em geral [9].

Apesar de ser considerada clinicamente benigna, há numerosos relatos de anormalidade associados ao traço falciforme, como os relatos de morte súbita em recrutas americanos portadores de traço falciforme após serem submetidos a exercícios físicos extenuantes. Um estudo retrospectivo sobre morte súbita durante treinamento envolvendo 2.000.000 (dois milhões) de recrutas das Forças Armadas dos Estados Unidos apresentou uma incidência de $1: 3.200$ entre os recrutas com traço falciforme, com um risco 28 (vinte e oito) vezes maior de morte súbita em relação aos negros que possuíam $\mathrm{Hb}$ AA (normal) e concluiu que os recrutas com traço falciforme em treinamento básico têm um risco substancialmente aumentado $[9,10]$.

A escolha do tema se deu pela busca de um melhor entendimento da doença e alta incidência na Região Nordeste, em especial, no 
Maranhão. Desta forma, optamos, neste trabalho, por utilizar as técnicas de Microscopia de Força Atômica e Espectroscopia Raman, pois ambas apresentam grande versatilidade para o estudo de amostras biológicas e alta precisão em medidas a nível de uma única célula.

Os primeiros estudos de ER em sistemas biológicos foram reportados na década de 90 , quando a técnica mostrou-se como um instrumento forte e eficaz para análise, detecção e monitoramento de patologias in vivo, por seu grande potencial de diagnóstico em tempo real, fazendo com que diversos pesquisadores utilizassem a técnica para a detecção precisa e minimamente invasiva de uma grande quantidade de tumores genitais, cerebrais, mamários e da laringe, revelando que a transição do tecido normal para o câncer está associada, significativamente, às diferenças nas estruturas bioquímicas, que são refletidas no espectro Raman [10-11].

Em nosso trabalho, utilizamos a Espectroscopia Raman para analisar e identificar as diferenças espectrais obtidas do grupocontrole e do grupo de pacientes portadores da doença falciforme, que foram previamente diagnosticados através do método convencional de identificação de hemoglobina.

Também utilizamos a técnica de Microscopia de Força Atômica que tem, como a principal vantagem para aplicação em amostras biológicas, a possibilidade de operação em condições ambiente ou solução aquosa (ambiente nativo das células) [12]. Destaca-se também, para esta técnica, uma grande vantagem em relação à preparação das amostras, que é relativamente simples, pois não requer congelamento, revestimento metálico, vácuo ou corantes, sendo possível analisar a célula ligada à lâmina de vidro sem tratamento de fixação. O AFM (Atomic Force Microscopy) é também uma ferramenta poderosa para obter detalhes de nanoestruturas e propriedades biomecânicas de amostras biológicas, podendo medir as alterações das propriedades mecânicas de membrana celular, rigidez e viscoelasticidade. Com a espectroscopia de força baseada em AFM, também é possível avaliar a adesão celular.

\section{MATERIAIS E MÉTODOS}

As amostras foram inicialmente solicitadas e coletadas no Centro de Hematologia e Hemoterapia do Maranhão-HEMOMAR de acordo com as normas dos Comitês de Ética daquela instituição e da Universidade Federal do Maranhão. Após a coleta, as amostras foram analisadas no menor tempo possível.

As medidas de ER foram realizadas utilizando-se o espectrômetro Horiba Jobin-Yvon, modelo T64000, com um sistema de detecção do tipo CCD (Charge Coupled Device) resfriado com nitrogênio líquido. Todas as medidas foram obtidas em geometria de retroespalhamento pelo modo single, utilizando a linha $532 \mathrm{~nm}$ com $5 \%$ da sua potência. Para as medidas, utilizamos um esfregaço que possuía sangue de doadores sadios como amostra controle e, para as medidas de anemia falciforme, utilizamos 3 (três) tipos de esfregaços. Esses grupos em estudo de portadores de anemias hemolíticas se subdividem em: AS, SC e SF.

A visualização da superfície da amostra foi realizada com o uso de um microscópio da marca Olympus, com câmera de vídeo acoplada. Para focalização do feixe sobre a superfície, utilizamos uma lente de 100x. Foram realizadas 3 (três) aquisições com tempos de 20 (vinte) segundos. A região espectral observada nos experimentos foi dívida nos intervalos 500 a $1700 \mathrm{~cm}^{-1}$.

A intensidade da radiação, por comprimento de onda, dos espectros obtidos na ER, serviu como base de dados, os quais foram submetidos à Análise de Componente Principal (PCA), que é uma técnica matemática que tem, por finalidade básica, a análise dos dados usados promovendo sua redução e eliminação de sobreposições. Por isso, pode ser usado como ferramenta estatística multivariada simples que transforma um conjunto de variáveis originais, que são extraídos da relação entre os dados (espectros), com as múltiplas variações, com uma transformada linear. O PCA pode ser usado para espectros de grupo de acordo com as respectivas variações semelhantes, uma vez que cada componente principal é ortogonal ao outro. Portanto, uma característica espectral original está presente em cada componente. Para calcular o componente principal dos espectros das hemácias, foi usado o software Origin 2018, com o qual utilizamos 20 (vinte) espectros de hemácias do grupo-controle e 18 (dezoito) espectros de hemácias do grupo de portadores de anemia falciforme.

Para análise no AFM, retirou-se, com um tubo capilar com heparina, uma gota de sangue do tubo de EDTA K3, depositou-se uma gota em lamínula de $13 \mathrm{~mm}$ e realizou-se um esfregaço (similar ao que se faz em hemocentros). As lamínulas foram aderidas no disco magnético do AFM usando fita dupla face e então levadas para análise com o AFM.

Para a análise da adesividade das hemácias, foi realizada uma varredura de $10 \mu \mathrm{m} \times 10 \mu \mathrm{m}$, sobre cada célula, analisando a célula por completo. Para a análise da rugosidade, realizou-se uma varredura de $1 \mu \mathrm{m} \times 1 \mu \mathrm{m}$ próximo ao centro da hemácia. As medidas de AFM foram realizadas com o Microscópio de Força Atômica Multimode Nanoscope 8 (Bruker).

Para os dados de AFM, quando a análise de rugosidade é aplicada a uma imagem, os valores estatísticos são calculados de acordo com as alturas de cada pixel na imagem e existem dois valores que são levados em consideração: $R_{\alpha}$ e $R_{q}$, onde $\circ R_{\alpha}$ é o valor de rugosidade média da superfície. A rugosidade média é apenas o perfil médio absoluto, não fazendo distinção entre picos e vales. A expressão utilizada para o cálculo dos valores de $R_{\alpha}$ é:

$R_{a}=\frac{1}{N} \sum_{j=1}^{N} Z_{j}$

$R_{\text {qa }}$ é o valor da raiz quadrada média da rugosidade e é uma função que leva em consideração o quadrado das medidas. $O R_{q}$ é mais sensível a picos e vales do que a rugosidade média e é proporcional ao quadrado da altura tomada em seu cálculo.

$R_{\mathrm{q}}=\sqrt{\frac{\sum Z_{\mathrm{i}}^{2}}{N}}$

Em cada célula foi escolhida uma área de 10 (dez) micrometros quadrados e obtido os valores de $R_{a}$ e $R_{\alpha}$.

Em cada amostra, foram analisadas 5 (cinco) células e, para cada célula, foram feitas varreduras de lateral 1 (um) micrometro. As análises dos dados de topografia, rugosidade, adesão e propriedades mecânicas em geral foram feitas utilizando os softwares NanoScope Analysis e Gwyddion.

As amostras foram inicialmente coletadas no Centro de Hematologia e hemoterapia do Maranhão - HEMOMAR e as medidas de Espectroscopia Raman e Microscopia de Força Atômica (AFM) foram realizadas na Central Multiusuário de Pesquisa em Nanomateriais e Biossistemas (CMPNB) do Departamento de Física da UFMA.

\section{RESULTADOS E DISCUSSÃO}

$\mathrm{Na}$ Fig. 2 são apresentados os espectros de determinados pontos das hemácias do cordão umbilical, que foram utilizadas como amostra-controle. Três pontos (borda, intermediário e centro) foram escolhidos para o mapeamento, a fim de identificar os espectros em determinadas regiões da hemácia. Percebemos que, à medida que nos direcionamos para o centro da hemácia, a intensidade dos espectros vai diminuindo, pois a concentração de hemoglobina é maior nas bordas e menor no centro. 


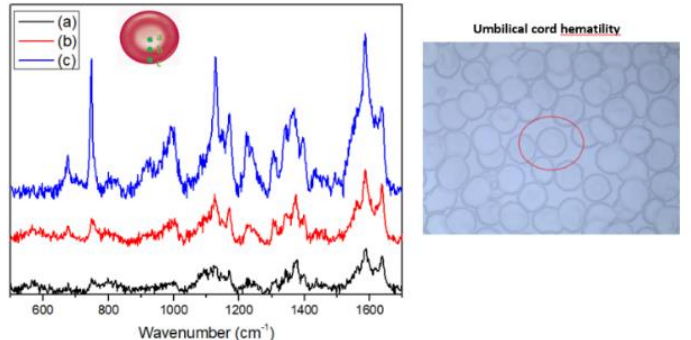

Figura 2. Espectros Raman e imagem do grupo controle.

A Fig. 3 mostra os espectros relacionados às hemácias dos diferentes tipos de portadores de anemia falciforme (AS, SC e SF). Ao correlacionar os espectros do grupo-controle, podemos notar a diferença tanto em posição e intensidade dos modos.

As diferenças espectrais das amostras do grupo-controle em relação às amostras de portadores de anemia falciforme, estão relacionadas às bandas nas regiões 882 e $1373 \mathrm{~cm}^{-1}$, atribuídas à Valina, que apresentam maior intensidade nos espectros dos portadores da doença. Enquanto que as bandas predominantes nos espectros do grupo controle, onde se encontram em 1547 e 1622 $\mathrm{cm}^{-1}$, são atribuídas ao Ácido Glutâmico [14]

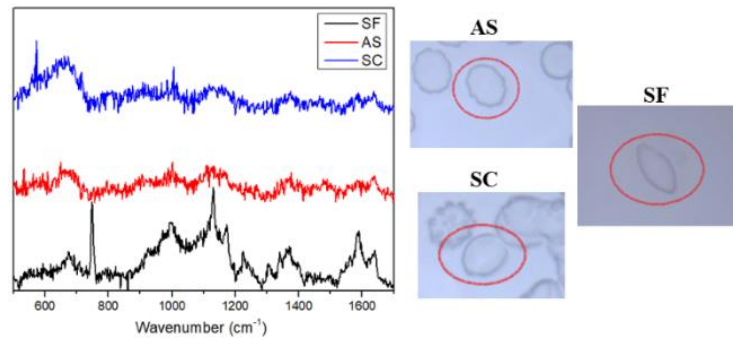

Figura 3. Espectros Raman e imagem do grupo de portadores da doença anemia falciforme (AS, SC e SF).

Comparando os espectros de ambas as figuras com relação às bandas de Valina e Glutamina, observamos significativa alteração nos modos relacionados ao ácido glutâmico, que aparecem mais definidos nas amostras de grupo-controle, e praticamente não aparecem no grupo de portadores de anemia falciforme. Também se verificaram, nos eritrócitos falcinados, alterações sutis nos modos do aminoácido de valina. Essa alteração sutil nos modos da Valina pode ser atribuída à banda de luminescência que aparece nessa região. Essa luminescência pode estar relacionada à suplementação de ferro a que os pacientes portadores de anemias hemolíticas costumam ser submetidos.

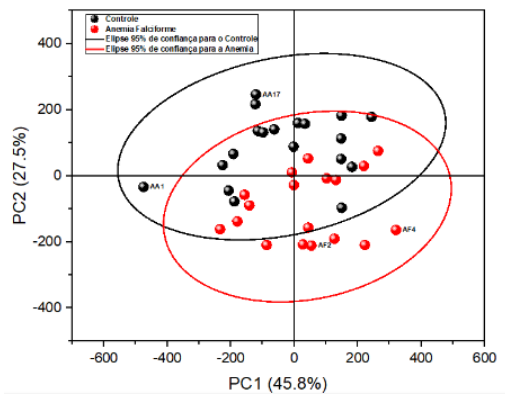

Figura 4. Gráfico PC1 vs PC2 para os dados obtidos dos espectros do grupo controle e grupo portadores de anemia falciforme.

No gráfico de PCA (Fig. 4), todos os pontos estão dentro da elipse de confiança de $95 \%$, onde PC1 $\rightarrow$ 45,8\% e PC2 $\rightarrow$ 27,5\%. Observamos que há uma diferença entre o grupo-controle e o grupo de portadores de anemia falciforme, apesar de haver uma região de sobreposição no gráfico de PC1-PC2. Esta sobreposição das elipses indica que os grupos compartilham de características próximas, mas aponta uma boa separação entre os eles. Este gráfico mostrou que o modelo PCA é uma boa ferramenta estatística para diagnósticos.

Visando compreender as propriedades físicas dos eritrócitos de portadores de anemia falciforme utilizamos também Microscopia de Força Atômica. Com essa técnica, é possível estudar as propriedades mecânicas em níveis macro, micro e nanoscópico da estrutura celular, muito além de usar forças interatômicas para gerar imagens topográficas de amostras. Com o AFM, há possibilidade de medir forças intermoleculares e a distribuição espacial dessas propriedades em uma única célula.

As imagens apresentadas na Fig. $\mathbf{5}$ foram obtidas com 0 Microscópio de Força Atômica (AFM). A imagem mostrada na Fig. 5 a revela a deformação que a célula (com $\mathrm{Hb}$ SS) apresenta quando sofre desoxigenação (assumindo forma de foice, motivo do nome falciforme). A imagem na Fig. 5b é de uma amostra de anemia falciforme, porém ainda não sofreu desoxigenação tendo, assim, forma semelhante às das células normais, como a da Figura $5 c$. Apesar de as células da Figura $\mathbf{5 b}$ terem esse aspecto aparentemente normal, há diversas características diferentes das células normais que foram reveladas pelas varreduras com AFM.

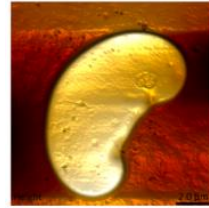

(a)

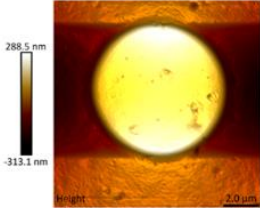

(b)

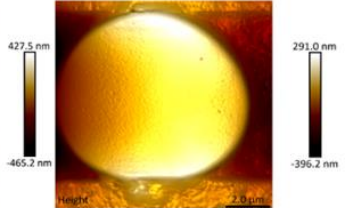

(c)
Figura 5. Imagens de Microscopia de Força Atômica (AFM) de (a) um eritrócito falcinado; (b) um eritrócito de portador de anemia falciforme (célula ainda com aspecto normal); e (c) um eritrócito de pessoa sem anemia falciforme.

Com a Microscopia de Força Atômica, analisamos os diferentes grupos de amostra (eritrócitos com $\mathrm{Hg} \mathrm{AA}, \mathrm{Hg} \mathrm{AS}, \mathrm{Hg} \mathrm{SC}$ e Hg SS). Nos casos de anemia falciforme, analisamos células com formato normais como a da Figura $\mathbf{5 b}$, sem estarem na forma característica da doença (Figura 5a).

Após varredura de $10 \mu \mathrm{m} \times 10 \mu \mathrm{m}$ sobre a célula, analisamos então a força de adesão que a celular exercia sobre a ponta e depois comparamos a adesão das hemácias com diferentes hemoglobinas, como mostrado na Fig. 6.
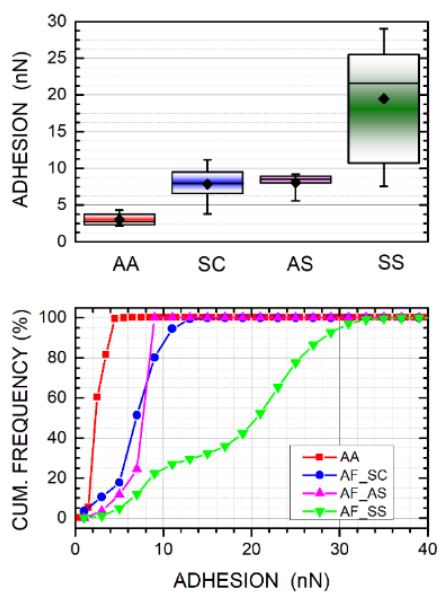

Figura 6 Adesão de eritrócitos com diferentes mutações na Hemoglobina.

O gráfico da Figura 6 mostra a adesão de eritrócitos com diferentes mutações na Hemoglobina. As siglas AA correspondem à adesão dos eritrócitos padrão, sem mutação nos genes que dão origem a hemoglobina; AS corresponde à adesão dos eritrócitos com traço falciforme, cujo um dos genes que dão origem à 
hemoglobina é o gene padrão e o outro é um gene variante característico da anemia falciforme; SC corresponde à adesão dos eritrócitos de portadores da doença da hemoglobina $S-C$, cujos 2 (dois) genes que dão origem à hemoglobina são variantes, um tipo $C$ e outro variante tipo $S$, que é característico da anemia falciforme. SS corresponde à adesão dos eritrócitos de portadores de anemia falciforme, cujos 2 (dois) genes são variantes tipo $S$, que, no estado homozigótico (como neste caso) causam a anemia falciforme.

No gráfico da adesão, observa-se que as células com hemoglobina AA apresentam menor adesividade, as células com hemoglobina SC e AS apresentam adesividade média próxima uma da outra e um pouco mais elevada que as células com hemoglobinas AA, o tipo SC apresenta um desvio médio maior que o tipo AS, tendo regiões mais adesivas e outras menos adesivas que o tipo AS. As células com hemoglobina SS, cujos portadores possuem anemia falciforme, apresentam uma adesividade muito mais elevada que as demais células.

Ainda sobre a adesão, no gráfico da frequência acumulativa, podemos identificar três regimes: (i) células normais, no qual todos os valores da força de adesão estão abaixo de $5 \mathrm{nN}$; (ii) com hemoglobina do tipo SC e AS que apresentam um deslocamento com crescimento acentuado, atingindo $90 \%$ dos valores até $11 \mathrm{nN}$; e (iii) do tipo SS, em que $40 \%$ dos valores estão abaixo de $20 \mathrm{nN}$, enquanto os demais são atingidos até $34 \mathrm{nN}$.

A adesividade das células maior que $\mathrm{O}$ normal deve estar diretamente relacionada com casos de acidente vascular cerebral (AVC), trombose, dentre outras, que são doenças causadas por coágulos no sangue, no qual uma adesividade mais elevada dos eritrócitos deve implicar também em uma maior probabilidade de formação destes coágulos (junção de células). A anemia falciforme $\mathrm{Hb}$ SS, em que temos que a adesividade é maior que as das demais células, representa um risco maior, não somente pela alta adesividade da celular, mas por, em baixa concentração de oxigênio, essas células assumirem formato de foice (Fig. 5a) que, além de seu formato se alterar nessa situação, a distribuição de cargas elétricas também muda. Normalmente os eritrócitos se repelem, pois apresentam cargas elétricas negativas. Devido à mudança de suas cargas elétricas por baixa disponibilidade de oxigênio, os eritrócitos deixam de se repelir e, podem agora se unir (grudar) um ao outro (devido à alta adesividade), juntando-se dentro de capilares ou vasos sanguíneos mais facilmente, gerando, assim, os diversos problemas associados a anemia falciforme como a crise de dor (sintoma mais frequente da doença falciforme causado pela obstrução de pequenos vasos sanguíneos pelos eritrócitos muito adesivos e falcinados), ocasionando maior probabilidade de ocorrer trombose ou AVC, dentre outros problemas que devem se relacionar com o aumento da adesão dos eritrócitos.

Após varredura de $1 \mu \mathrm{m} \times 1 \mu \mathrm{m}$ sobre a superfície da célula, analisamos a rugosidade da membrana externa das células e comparamos a rugosidade das hemácias com diferentes hemoglobinas como mostrado na Fig. 7.

Observa-se que a rugosidade das células de doadores não portadores de anemia é mais elevada que a das células que têm hemoglobinas variantes, seguindo características observadas em outros trabalhos que estudaram anomalias em hemácias [16]. A rugosidade da superfície da membrana tem se mostrado um importante parâmetro morfológico das hemácias, observando que a integridade do citoesqueleto da membrana celular, mediada como rugosidade da superfície, é associada ao estado funcional da célula, tendo em células de amostras patológicas diminuição da rugosidade da membrana. A rugosidade da célula normal apresenta-se bem elevada em comparação com as demais amostras. Comparando as amostras SF e AS, temos uma rugosidade similar, porém, o grupo SF apresenta rugosidade ligeiramente mais elevada, apesar de ser uma célula também falcinada. Isso deve-se provavelmente ao alto índice de hemoglobina fetal que ameniza um pouco o efeito da hemoglobina $S$ sobre as células, dando assim característica similar a das células AS.
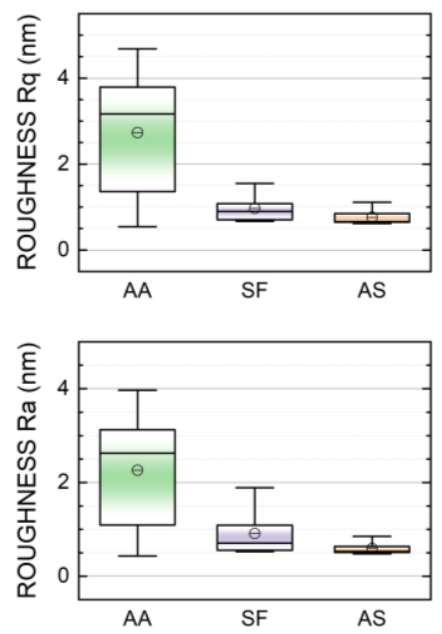

Figura 7. Rugosidade das células com hemoglobina normais, SF e AS, Rq é Ra são rugosidade media da amostra.

\section{CONCLUSÕES}

A Espectroscopia Raman é uma técnica analítica e não destrutiva que produz informações sobre a estrutura molecular dos tecidos em investigação em poucos instantes, onde a análise e comparação dos espectros de amostras de grupos-controle, com aqueles de amostras de grupos portadores de alguma enfermidade, leva à caracterização espectral da patologia estudada.

$\mathrm{Na}$ perspectiva de diagnosticar grupos com anemia falciforme através da Espectroscopia Raman, foram submetidas à análise com esta técnica hemácias de doadores sadios como grupo-controle, e hemácias de doadores portadores de anemia falciforme. Mapearam-se determinadas regiões das células analisadas dos grupos distintos, o que possibilitou verificar diferenças nos espectros devido à concentração de hemoglobina presente. 0 estudo dos espectros de anemia falciforme, mostrou mudanças significativas nas bandas do ácido glutâmico e alterações sutis nas bandas do aminoácido valina, o que aponta para um marcador característico da presença da enfermidade em estudo.

A técnica de estatística multivariada de análise de componente principal (PCA) foi utilizada para desenvolver um algoritmo de classificação para diagnósticos. 0 gráfico de PCA revelou distribuição local dispersa no espaço entre os grupos PC1-PC2.

A Microscopia de Força atômica mostrou-se uma ferramenta de grande utilidade na análise dos biossistemas em foco. Dois foram os parâmetros investigados com esta técnica: adesão e rugosidade. A análise da adesão, medida com a ponta AFM, de células normais, com traço falciforme, com gene da anemia falciforme e células falcinadas, revelou expressiva diferença entre os grupos estudados, ainda que as imagens topográficas das células apresentassem aspecto padrão. 0 parâmetro de rugosidade da membrana, coletada sobre as mesmas células que serviram de amostra para a adesão, indicou distinta identidade entre as células normais, e aquelas de doadores portadores de anemia falciforme. Para um dos grupos de células analisados, ainda que apresentando apenas o traço falciforme, a rugosidade da membrana também mostrou-se como parâmetro indicador da patologia. Tais diferenças, de adesão e rugosidade, podem estar associadas a diversas características da mutação causada pela hemoglobinopatias. O entendimento do papel destas características pode levar a novas formas de tratamentos. 


\section{REFERÊNCIAS}

WHO Working Group. Hereditary anemias: genetics basis, clinical features, diagnosis and treatment, WHO, v. 60, p. 643-660, 1982.

WILLARD, H. H.; MERRITT, L. L.; DEAN, J. A. \& SETTLE, F. A. Instrumental Methods of Analysis, 7 ed., Belmonte, CA: Wadsworth Publishers, 1988.

NUZZO, D. V. P. D.; FONSECA, S. F. Anemia falciforme e infecções. Jornal de Pediatria, scielo, v. 80, p. 347 - 354, 002004. ISSN 0021-7557.

NETO, G. C. d. G.; PITOMBEIRA, M. d. S. Aspectos moleculares da anemia falciforme. Jornal Brasileiro de Patologia e Medicina Laboratorial, scielo, v. 39, p. 51 - 56, 00 2003. ISSN 1676-2444.

SAIZ, A.; RODRIGUEZ, J.A. Respuesta inmune humoral antitreptococcus pneumoniae en pacientes con anemia de celulas falciformes: Descripcion de un caso. Rev. Asoc. Colomb. Alerg. Inmunol., v. 8, n. 3, p. 54-54, 1999.

[6] FELIX, A. A.; SOUZA, H. M.; RIBEIRO, S. B. F. Aspectos epidemias e sociais da Doença falciforme. Revista Brasileira de Hematologia e Hemoterapia , scielo, v. 32, p. 203- 208, 002010. ISSN 1516-8484

[7] SILVA, L. P. A. d.; NOVA, C. V.; LUCENA, R. Anemia falciforme e surdez infanto-juvenil: revis ${ }^{2}$ da literatura.Brazilian Journal of Otorhinolaryngology, scielo, v. 78, p.126 - 131, 02 2012. ISSN 18088694

[8] ARAUJO, J. A. de Jesus. Paulo Ivo Cortez de. Doença falciforme: condutas básicas para tratamento / Sickle cell disease: basic management for treatment. [S.I.]: S 'erie B.Textos B asicos de Sa'ude, 2012. 01 - 64 p.

[9] KARK, J. A. et al. Sickle-cell trait as a risk factor for sudden death in physicaltraining. New England Journal of Medicine, v. 317, n. 13, p. 781-787, 1987. PMID:3627196. Dispon ivel em:<https: / /doi.org/10.1056/NEJM198709243171301> [10] SCHUT, T. C. B.; WOLTHUIS, R.; CASPERS, G. J. Real-time tissue characterization on the basis of in vivo Raman spectra. $J$ Raman Spectrosc, v.33, n.7, p.580-585, 2002.

[11] STONE, N. Near-infrared Raman spectroscopy for the classification of epithelial pre-cancers and cancers. J Raman Spectrosc, v.33, 564-573, 2002.

[12] CHANG, K.-C. et al. Atomic force microscopy in biology and biomedicine.Tzu ChiMedical Journal, v. 24, n. 4, p. $162-169$, 2012. ISSN 1016-3190. Disponível em: <http://www.sciencedirect.com/science/article/pii/S1016319 012000845>

[13] HISCH, R. E.; JUSZCHQ, L. J.; NAZIM, A. F. et al. Solutionactive Structural alterations in linked hemoglobin $C(B 6 G l u \rightarrow$ Val). J. Biol. Chem. 274(20): 13777- 13782, 1999.

[14] MAHADEVAN-JANSEN, A.; RICHARDSKORTUM, R. Raman Spectroscopy for cancer detection: A review. Proceedings - 19th International Conference, p.2722-2828, 1997.

[15] Natasha Yeow, Rico F. Tabor, Gil Garnier , Atomic force microscopy: From red blood cells to immunohaematology, Advances in Colloid and Interface Science,v. 249, 149-162, 2017. 